Corrigendum

\title{
Corrigendum to "Acute-on-Chronic Liver Failure in Pregnant Patients with Chronic Hepatitis B: A Retrospective Observational Case Series Study"
}

\author{
Shiwei Wang, ${ }^{1}$ Haofeng Xiong, ${ }^{2}$ Changling Luo, ${ }^{1}$ Hong Zhao, ${ }^{1}$ Ying Fan, ${ }^{1}$ Ting Zhang, \\ Lili Wang," Qi Wang," and Wen Xie \\ ${ }^{1}$ Department of the Liver Center, Beijing Ditan Hospital, Capital Medical University, No. 8 Jingshundong Street, Chaoyang District, \\ Beijing 100015, China \\ ${ }^{2}$ Department of Critical Care Medicine, Beijing Ditan Hospital, Capital Medical University, No. 8 Jingshundong Street, \\ Chaoyang District, Beijing 100015, China \\ Correspondence should be addressed to Wen Xie; xiewen6218@163.com
}

Received 11 November 2020; Accepted 11 November 2020; Published 20 November 2020

Copyright ( 2020 Shiwei Wang et al. This is an open access article distributed under the Creative Commons Attribution License, which permits unrestricted use, distribution, and reproduction in any medium, provided the original work is properly cited.

In the article titled "Acute-on-Chronic Liver Failure in Pregnant Patients with Chronic Hepatitis B: A Retrospective Observational Case Series Study" [1], the acknowledgements should read as follows:

"This article was supported by Beijing Municipal Science and Technology Commission (D171100003117005); Digestive Medical Coordinated Development Center of Beijing Hospitals Authority (XXZ0402); Beijing Hospitals Authority of Hospitals Clinical Medicine Development of Special Funding Support (ZYLX201808)."

\section{References}

[1] S. Wang, H. Xiong, C. Luo et al., "Acute-on-chronic liver failure in pregnant patients with chronic hepatitis B: a retrospective observational case series study," Gastroenterology Research and Practice, vol. 2020, Article ID 9831687, 8 pages, 2020. 